\title{
Erratum to: The Kinetics of CO Oxidation by Adsorbed Oxygen on Well-Defined Gold Particles on $\mathrm{TiO}_{2}(110)$
}

\author{
V. Bondzie $\cdot$ S. C. Parker $\cdot$ Charles T. Campbell
}

Published online: 26 August 2011

(C) Springer Science+Business Media, LLC 2011

\section{Erratum to: Catal Lett 63:143-151 (1999) DOI 10.1023/A:1019012903936}

On page 149 , the text of this paper reads:

"Using simple Redhead analysis [28] and assuming first order desorption kinetics and a pre-exponential factor for desorption of $5.5 \times 10^{12} \mathrm{~s}^{-1}$ from a closely related $\mathrm{O} / \mathrm{Au}$ system [22], we estimate desorption activation energies ranging from $124.7 \mathrm{~kJ} / \mathrm{mol}$ (for the $\sim 1$-atom thick islands) to $90.4 \mathrm{~kJ} / \mathrm{mol}$ (for the 6-atom thick islands). Since the activation energy for desorption generally follows the same trend as the adsorption energy (and they are equal for nonactivated adsorption), we conclude that the $\sim 34.3 \mathrm{~kJ} / \mathrm{mol}$ higher activation energy on the thinnest particles corresponds to a larger adsorption energy (i.e., considerably more stable $\mathrm{O}_{\mathrm{a}}$ ) on the thinnest particles of Au."

There was a calculation error here, and these three energies must be changed so that this text instead reads:

"Using simple Redhead analysis [28] and assuming first order desorption kinetics and a pre-exponential factor for desorption of $5.5 \times 10^{12} \mathrm{~s}^{-1}$ from a closely related $\mathrm{O} / \mathrm{Au}$ system [22], we estimate desorption activation energies ranging from $190 \mathrm{~kJ} / \mathrm{mol}$ (for the $\sim 1$-atom thick islands) to $139 \mathrm{~kJ} / \mathrm{mol}$ (for the 6-atom thick islands). Since the activation energy for desorption generally follows the same trend as the adsorption energy (and they are equal for nonactivated adsorption), we conclude that the $\sim 51 \mathrm{~kJ} / \mathrm{mol}$ higher activation energy on the thinnest particles corresponds to a larger adsorption energy (i.e., considerably more stable $\mathrm{O}_{\mathrm{a}}$ ) on the thinnest particles of Au."

Correspondingly, the value of " $34.3 \mathrm{~kJ} / \mathrm{mol}$ " appearing in three other places (on Figure 9, in the right-hand column of page 149 and the left-hand column of page 150) all must be corrected also to be " $51 \mathrm{~kJ} / \mathrm{mol}$ ". Similarly, the value " $>17.2 \mathrm{~kJ} / \mathrm{mol}$ " appearing in two places (on Figure 10 and in the left-hand column of page 150) must be corrected in both places to be " $>25 \mathrm{~kJ} / \mathrm{mol}$ ".

The authors thank Dr. Beatriz Roldan Cuenya for pointing out this error.

The online version of the original article can be found under doi:10.1023/A:1019012903936.

V. Bondzie · S. C. Parker · C. T. Campbell ( $₫)$

Department of Chemistry, University of Washington, Seattle,

WA 98195-1700, USA

e-mail: campbell@chem.washington.edu 